\title{
«Research Note» \\ Effect of Varying Proportions of Lignin and Cellulose Supplements on Immune Function and Lymphoid Organs of Layer Poultry (Gallus gallus)
}

\author{
Sherzad M. Hussein ${ }^{1,2}$ and Theresa L. Frankel ${ }^{1}$ \\ ${ }^{1}$ Department of Physiology, Anatomy and Microbiology, School of Life Sciences, \\ La Trobe University, Victoria, 3086, Australia \\ ${ }^{2}$ University of Duhok, Duhok, Kurdistan Region, Iraq
}

\begin{abstract}
To determine the benefits of different types or proportions of insoluble fiber components on growth and immunity, 4-week-old commercial layer pullets were fed supplements containing different proportions of purified lignin and cellulose or a commercial lignocellulose supplement. The $64 \mathrm{Hy}$-Line Brown pullets were provided basal diets supplemented with $1 \mathrm{~g}$ fiber per $100 \mathrm{~g}$ diet. The supplements included a commercial lignocellulose, Arbocel $^{\circledR}$ $\mathrm{RC}$ fine (group A) with cellulose to lignin ratio of approximately 3:1, cellulose (group Ce), a 3:1 mixture of cellulose: lignin (group Ce3Lig1), and a 2:1 mixture of cellulose: lignin (group Ce2Lig1). After 3 weeks, innate immune function was measured in terms of heterophil phagocytosis and oxidative burst $(n=8)$. After 4 weeks, ex vivo stimulated lymphocyte proliferation was determined for assessment of cell-mediated immune function $(n=7)$. All pullets were killed at 9 weeks of age and lymphoid organs were weighed $(n=16)$ and small intestinal Peyer's patches (PP) were measured $(n=8)$. Pullets in both A and Ce3Lig1 groups had heavier $(P<0.05)$ body and bursa of Fabricius weights. The number of $\mathrm{PP}$ in group A was higher $(P<0.05)$ than in group Ce. The percentage of heterophil phagocytosis in A and Ce3Lig1 groups were higher $(P<0.05)$ than in group Ce, and oxidative burst of group A was higher $(P<0.05)$ than that of group Ce. Addition of 1\% Arbocel or 1\% Ce3Lig1 to the diet of layer pullets from 4 to 9 weeks of age significantly improved their growth and innate immune function compared to group Ce. This suggests that lignin either modulates the effect of cellulose or has specific mechanisms of action in the gut that improves growth and immunity. The proportion of lignin to cellulose may also be important for growth and immune function.
\end{abstract}

Key words: heterophils, insoluble fiber, lymphocytes, oxidative burst, Peyer's patches, phagocytosis

$$
\text { J. Poult. Sci., 56: 71-77, } 2019
$$

\section{Introduction}

The potential of dietary insoluble fiber (IF) to improve immunity of poultry has been extensively investigated in the past decade. Although different feed ingredients or supplements have been used as dietary sources of IF (McReynolds et al., 2009; Faber et al., 2012; Jiang et al., 2014; Sadeghi et al., 2015; Hussein et al., 2017), the chemical composition and proportions of the main IF components, namely, lignin and cellulose, in these ingredients vary considerably (Bach Knudsen, 1997).

Lignin and cellulose exert beneficial prebiotic effects on the bacterial species and structure of the intestinal tract of poultry (Ricke et al., 1982; Yu et al., 1998; Cao et al., 2003; Shakouri et al., 2006; Baurhoo et al., 2007, 2008; Faber et

Received: March 4, 2018, Accepted: June 6, 2018

Released Online Advance Publication: August 25, 2018

Correspondence: Dr. Sherzad M. Hussein, Department of Animal Production, College of Agriculture, University of Duhok, Duhok, Kurdistan Region, Iraq. (E-mail: sherzad.hussein@uod.ac) al., 2012; Bogusławska-Tryk et al., 2015). The phenolic units of purified lignin possess antimicrobial characteristics, and lignin has a beneficial effect on the production and health of broilers (Baurhoo et al., 2008). Compared to the unsupplemented controls, lignin affected the gut-associated lymphoid tissue of poultry by increasing $\mathrm{CD}^{+}$and $\mathrm{CD} 8^{+}$ lymphocyte subpopulations in the duodenum (Revajová et al., 2013). Cellulose as a feed supplement increases the population of beneficial intestinal microflora and decreases the number of harmful microorganisms, thereby reducing the deleterious effects of potential pathogens in poultry (Cao et al., 2003; Shakouri et al., 2006; Saki et al., 2010).

We recently showed that supplementing the diet of layer pullets with two commercial lignocellulose products of different fiber compositions elicited beneficial but different effects on heterophil function, lymphocyte proliferation, and the number of Peyer's patches (PP) (Hussein et al., 2017). However, the effects of feeding IF supplements containing different proportions of purified lignin and cellulose on the immune functions of layer pullets have not been investigated. 
Therefore, we aimed to determine whether different proportions of lignin and cellulose added to the diets of 4-weekold Hy-Line Brown layer strain pullets elicit similar immune responses to those produced by the commercial lignocellulose supplement, Arbocel ${ }^{\circledR}$ RC fine (Hussein et al., 2017).

\section{Materials and Methods}

\section{Experiment Design, Management, and Diets}

Sixty-four 4-week-old healthy Hy-Line Brown pullets were randomly selected from a single shed on a commercial farm. The pullets were weighed, leg-banded, and randomly placed into 16 pens $(1.8 \mathrm{~m}$ long $\times 0.9 \mathrm{~m}$ wide $\times 1.8 \mathrm{~m}$ high) with slatted floors. All pens were located in one insulated closed shed ventilated with a permanent vent in the roof ridge and an evaporative ventilation and cooling system with internal distribution via an overhead sausage. The shed had an ambient temperature between 20 to $23^{\circ} \mathrm{C}$ and light interval of $12 \mathrm{~h}$ from $07: 30$ to $19: 30 \mathrm{~h}$. The pullets had access to fresh water and food at all times.

The four treatment groups of 16 birds each, with four pullets/pen were fed the same basal diet. Pullet starter diet and grower diet were fed from 4-8 weeks and 8-9 weeks of age, respectively (Table 1, Barastoc ${ }^{\mathrm{TM}}$ Chick Starter feed and Barastoc $^{\mathrm{TM}}$ Pullet Grower feed, Ridley AgriProducts Pty Ltd., Australia, http://www.agriproducts.com.au). For the four dietary treatments, $1 \mathrm{~g}$ of different IF supplements were added to $100 \mathrm{~g}$ of the commercial basal diets. The group A (the standard or control treatment group) diet was supplemented with the lignocellulose product, Arbocel ${ }^{\circledR} \mathrm{RC}$ fine ( $\mathrm{J}$. Rettenmaier and Söhne GmbH and Co., Rosenberg, Germany. Manufacturer's analyses: $65-70 \mathrm{~g}$ crude fiber $/ 100 \mathrm{~g}$, high in insoluble cellulose and $>20 \mathrm{~g}$ lignin/ $100 \mathrm{~g}$ ) and that of Group Ce was supplemented with cellulose (JustFiber ${ }^{\circledR}$
20, C4042C (100\% cellulose), Agri Food Ingredients, N G Alexander and Co. Pty Ltd, Kew East, Victoria, Australia). The group Ce3Lig1 diet was supplemented with $3: 1$ cellulose: lignin mixture and that of group Ce2Lig1with 2:1 cellulose: lignin mixture. The lignin used was annual fiber soda pulped lignin, which contained $>98 \mathrm{~g}$ lignin $/ 100 \mathrm{~g}$ (Protobind $^{\mathrm{TM}}$ 1000, Greenvalue, SA, USA), and was kindly supplied by Les Edye and Albert Tietz, BioIndustry Partners Pty Ltd, Nerang Business Centre, Queensland, Australia.

The crude fiber concentrations (g/100 g diet) analyzed by FeedTest (Agrifood Technology Pty Ltd., Victoria, Australia) were A, 3.11; Ce, 3.44; Ce3Lig1, 3.44; Ce2Lig1, 3.43 in the four starter diets, and A, 5.29; Ce, 5.62; Ce3Lig1, 5.62; Ce2Lig1, 5.61 in the four grower diets.

\section{Sample Collection and Lymphoid Organ Measurements}

Three weeks after starting the experiment, eight blood samples per treatment (two/pen) were collected for measurement of two heterophil innate immune functions, namely, phagocytosis and oxidative burst. Four weeks after starting the experiment, seven blood samples per treatment (1-2/pen) were collected from pullets other than those used previously, for measurement of cell-mediated immune function by mitogen-stimulated lymphocyte proliferation in isolated lymphocytes. After five weeks, all pullets were killed with an overdose of Lethabarb (Virbac Animal Health, Milperra, NSW, Australia). The lymphoid organs from all pullets were weighed and the combined jejunum and ileum from eight pullets/treatment were collected and stored at $-20^{\circ} \mathrm{C}$ for PP measurements.

For PP measurements, the thawed intestines were soaked in an aqueous solution of $5 \mathrm{~m} l$ acetic acid $/ 100 \mathrm{~m} l$ deionized water, stained with an aqueous solution of $0.5 \mathrm{~g}$ polychrome methylene blue (Amber Scientific, Australia)/100 ml (Cornes,

\begin{tabular}{lcc}
$\begin{array}{l}\text { Table 1. Chemical composition }(\mathbf{g} / \mathbf{1 0 0} \text { g) of Barastoc Chick Starter } \\
\text { and Pullet Grower feeds (Manufacture's } \\
\text { information }{ }^{\mathbf{1}} \text { ) }\end{array}$ \\
\hline \hline \multicolumn{1}{c}{ Chemical composition ${ }^{2}$} & Chick Starter & Pullet Grower \\
\hline \hline Dry matter & 86 & 86 \\
Moisture & 14 & 14 \\
Protein & 19.5 & 15.5 \\
Fat (minimum) & 2.5 & 2.5 \\
Fiber (maximum) & 6 & 8 \\
ME MJ/kg & 11.92 & 11.30 \\
Salt (added maximum) & 0.3 & 0.3 \\
Total phosphorous (minimum) & 0.65 & 0.64 \\
Available phosphorous (minimum) & 0.5 & 0.5 \\
Calcium (minimum) & 1 & 1
\end{tabular}

1 - Ridley AgriProducts Pty Ltd., Pakenham, 3810, Australia.

2 - Feed analysis and ingredients were obtained from the manufacturer but the quantities used were not disclosed for maintaining confidentiality.

3 - Converted from $\mathrm{kcal} / \mathrm{kg}$ by multiplying by 4.184 .

Ingredients used were: wheat, barley, field peas, meat and bone meal, beef tallow, canola meal expeller, soybean meal, canola seed, Millrun wheat by-product mix, oat hulls, limestone, mono-dicalcium phosphate (Biofos MDCP), salt, sodium bicarbonate, choline chloride, methionine, lysine, vitamin and mineral premix, phytase, and xylanase. 
1965), and photographed. The number of PP in each intestine was recorded from the images and the surface areas of PP $>1 \mathrm{~mm}^{2}$ were measured (Hussein et al., 2017) using the AutoCAD ${ }^{\circledR}$ computer software (Autodesk AutoCAD ${ }^{\circledR}$ Design Suite, 2014, USA). The total areas of PP were calculated for each sample, which were expressed relative to the surface area of the combined jejunum and ileum.

Experimental procedures were approved by the Animal Ethics Committee of La Trobe University (approval number LTU AEC14-52).

\section{Measurement of Heterophil Phagocytosis and Oxidative Burst}

The methods used have been described in detail in Hussein et al. (2017) and are briefly described here. Heterophils were isolated using a discontinuous gradient of Histopaque$1077^{\circledR}$ (number 10771, Sigma-Aldrich, Castle Hill, NSW, Australia) layered over Histopaque-1119 ${ }^{\circledR}$ (number 11191, Sigma-Aldrich), and viability was determined by the trypan blue exclusion method. On the day of isolation, phagocytosis of latex beads $(1.1 \mu \mathrm{m}$ mean particle size, number: LB11, Sigma-Aldrich) was performed in duplicate in sterile, 4chamber cover glass slides (Lab-Tek ${ }^{\mathrm{TM}}$ II CC2, Thermo Fisher Scientific Australia Pty Ltd). After $30 \mathrm{~min}$ incubation, the slides were stained with Wright's stain and examined under oil-immersion microscopy. Phagocytosis index (PI) was calculated as the total number of latex beads phagocytized by the first 100 heterophils counted, and phagocytosis percentage $(\% \mathrm{P})$ was calculated as the proportion of 100 heterophils that phagocytized at least one latex bead.

On the same day, oxidative burst was measured after incubating heterophils with the mitogen, phorbol 12-myristate 13-acetate (PMA, number P8139, Sigma-Aldrich) and substrate 2', 7'-dichlorofluorescin diacetate (number D6883, Sigma-Aldrich) for $1 \mathrm{~h}$. Intensity of the fluorescent product $2^{\prime}, 7^{\prime}$-dichlorofluorescein was determined using a fluorescence microplate reader (EnSpire ${ }^{\circledR}$, PerkinElmer Co, USA) at $485-\mathrm{nm}$ excitation and $530-\mathrm{nm}$ emission. Results were expressed as $\triangle \mathrm{RFU}$, a change in relative fluorescent units (RFU) of PMA-stimulated cells compared to the RFU of non-stimulated cells (Wan et al., 1993; He et al., 2007).

\section{Measurement of Lymphocyte Proliferation}

The methods used have been described in detail in Hussein et al. (2017) and are briefly described here. Lymphocytes were separated from peripheral blood using Histopaque$1.077^{\circledR}$ and the viability of isolated cells was determined by trypan blue exclusion. Mitogen-stimulated proliferation of lymphocytes was assessed using concanavalin A (ConA, 2.5 $\mu \mathrm{g} / \mathrm{m} l$ ) from Canavalia ensiformis (Type: IV-S, product no. C5275, Sigma-Aldrich) as a T-lymphocyte agonist, lipopolysaccharide (LPS, $3.125 \mu \mathrm{g} / \mathrm{m} l$ ) from Escherichia coli 055:B5 (product no. L6529, Sigma-Aldrich) as a B-lymphocyte agonist, and PMA $(1.25 \mu \mathrm{g} / \mathrm{m} l)$ as a T and B lymphocyte stimulating agonist (Palacios et al., 2007). After incubating lymphocytes for 2.5 days, alamarBlue ${ }^{\circledR}$ (BUF012B, AbD Serotec, Oxford, UK) was added and incubated for $8 \mathrm{~h}$. Following reduction of alamarBlue ${ }^{\circledR}$, absorbance was measured at $570 \mathrm{~nm}$ and $600 \mathrm{~nm}$ using an EnSpire ${ }^{\circledR}$ microplate reader.
Proliferation was expressed as a proportionate increase in the number of mitogen-stimulated lymphocytes relative to nonstimulated lymphocytes.

\section{Statistical Analysis}

There were no significant differences in the mean body weights among the four pens within the same treatment, and therefore, all data were analyzed on an individual bird basis. All normally distributed data were analyzed using one-way analysis of variance (ANOVA); means were compared using Tukey's multiple range test (IBM SPSS 23.0 for Windows, USA) when there was a significant difference among treatment. Non-parametric Kruskal-Wallis one-way analysis of variance was used to analyze data that were not normally distributed. Mann-Whitney $U$ test was used to compare the means (Gibbons and Chakraborti, 2011) if there were significant differences. $P<0.05$ indicated statistical significance.

\section{Results and Discussion}

\section{Lymphoid Organs}

The absolute weights of the bursa of Fabricius were higher $(P<0.05, n=8)$ in groups A and Ce3Lig1 than in group Ce, but not in group Ce2Lig1 (Table 2). The weights and relative weights (RW, g/100 body weight (BW)) of other lymphoid organs also differed, although not significant; the absolute weights of the thymus, spleen, and cecal tonsils, and the RW of the bursa, thymus, and spleen of group A were heavier than those of group Ce; the absolute weights of the thymus and cecal tonsils and the RW of bursa, thymus, and cecal tonsils of group Ce3Lig1 were heavier than those of group Ce; the bursal absolute weight of group Ce2Lig1 was heavier, although not significantly, than that of group $\mathrm{Ce}$ (Table 2).

The reported effects of different sources of IF on the lymphoid organs of poultry vary (Zhang et al., 2008; Akhtar et al., 2012), which suggests that differences in the chemical composition of IF can affect the growth of lymphoid organs differently. However, we could not identify the specific causes contributing to the differences in treatments with different types or proportions of lignin, cellulose, or other lignocellulose compounds; nonetheless, lymphoid organ development may be affected, for example, by changes in the proportions of beneficial and pathogenic microorganisms in the gut (Baurhoo et al., 2007; McReynolds et al., 2009; Bogusławska-Tryk et al., 2015), and improvements in amino acid absorption (Farran et al., 2017) may increase availability of arginine (Kwak et al., 1999) and threonine (Corzo et al., 2007), thereby improving lymphoid organ growth.

The weights $(0.94 \pm 0.04 \mathrm{~g})$ and RW $(0.11 \pm 0.01 \mathrm{~g} / 100 \mathrm{~g}$ BW) of the bursa of Fabricius in the 9-week-old pullets in this study were $77 \%$ and $81 \%$ lower than those $(4.1 \pm 0.15 \mathrm{~g}$ and $0.58 \pm 0.02 \mathrm{~g} / 100 \mathrm{~g} \mathrm{BW}$ ) observed previously (Hussein $e t$ al., 2017) in 8-week-old pullets of the same strain reared from 4 weeks of age under the same conditions and fed the same basal diet and batch of Arbocel ${ }^{\mathbb{B}}$ supplement. In contrast to the bursae, the weights and RW of the thymus and spleen in this study were only lower by $14-30 \%$ of those 
Table 2. Live body weights (BW), measurements of immune organs and tissues, heterophil function, and lymphocyte proliferation of $\mathrm{Hy}$-Line Brown layer strain pullets administered four diets containing different types of purified dietary fiber from 4 to 9 weeks of age

\begin{tabular}{|c|c|c|c|c|c|}
\hline Dietary treatment ${ }^{1}$ & A & $\mathrm{Ce}$ & Ce3Lig1 & Ce2Lig1 & Pooled SEM \\
\hline Initial $\mathrm{BW}^{2}(\mathrm{~g})$ & 350 & 349 & 346 & 354 & 2.88 \\
\hline Final BW (age - 9 week) ${ }^{\dagger}(\mathrm{g})$ & $821^{\mathrm{a}}$ & $762^{\mathrm{b}}$ & $834^{\mathrm{a}}$ & $797^{\mathrm{ab}}$ & 6.69 \\
\hline \multicolumn{6}{|l|}{ Absolute weights (g) } \\
\hline Bursa of Fabricius & $0.94^{\mathrm{a}}$ & $0.72^{\mathrm{b}}$ & $0.91^{\mathrm{a}}$ & $0.81^{\mathrm{ab}}$ & 0.025 \\
\hline Thymus & 4.8 & 4.3 & 4.9 & 4.3 & 0.13 \\
\hline Spleen & 2.7 & 2.5 & 2.4 & 2.4 & 0.06 \\
\hline Cecal tonsils & 0.27 & 0.26 & 0.29 & 0.34 & 0.015 \\
\hline \multicolumn{6}{|l|}{ Relative weights (g/100g BW) } \\
\hline Bursa of Fabricius & 0.11 & 0.09 & 0.11 & 0.10 & 0.003 \\
\hline Thymus & 0.59 & 0.56 & 0.58 & 0.54 & 0.015 \\
\hline Spleen & 0.33 & 0.32 & 0.29 & 0.31 & 0.006 \\
\hline Cecal tonsils & 0.033 & 0.034 & 0.034 & 0.043 & 0.0018 \\
\hline Area of jejunum + ileum $\left(\mathrm{cm}^{2}\right)$ & 135.5 & 133.6 & 132.8 & 130.8 & 2.52 \\
\hline \multicolumn{6}{|l|}{ Small intestinal PP } \\
\hline Number & $11.1^{\mathrm{a}}$ & $8.8^{\mathrm{b}}$ & $10.6^{\mathrm{ab}}$ & $9.1^{\mathrm{ab}}$ & 0.31 \\
\hline Area $\left(\mathrm{cm}^{2}\right)$ & 2.9 & 2.3 & 2.6 & 2.5 & 0.10 \\
\hline $\begin{array}{l}\text { Relative area (area of } \\
\mathrm{PP} / \text { area of jejunum }+ \text { ileum) }\end{array}$ & 2.1 & 1.7 & 2.0 & 1.9 & 0.06 \\
\hline \multicolumn{6}{|l|}{ Heterophil activity } \\
\hline $\mathrm{PI}^{3}$ (latex beads/100 cells) & 420.3 & 371.8 & 402.1 & 394.6 & 9.28 \\
\hline $\begin{array}{l}\% \mathrm{P}^{4} \text { (proportion of } 100 \text { cells } \\
\text { containing } 1 \text { or more beads) }\end{array}$ & $80.4^{\mathrm{a}}$ & $73.5^{\mathrm{b}}$ & $77.8^{\mathrm{a}}$ & $76.6^{\mathrm{ab}}$ & 0.67 \\
\hline Oxidative burst $(\triangle \mathrm{RFU})^{5}$ & $8850^{\mathrm{a}}$ & $7732^{\mathrm{b}}$ & $8725^{\mathrm{ab}}$ & $7937^{\mathrm{ab}}$ & 162.6 \\
\hline \multicolumn{6}{|l|}{ Lymphocyte proliferation $^{6}$} \\
\hline ConA stimulated & 93.8 & 80.4 & 89.1 & 90.0 & 2.12 \\
\hline LPS stimulated & 102.2 & 98.6 & 104.4 & 101.5 & 1.71 \\
\hline PMA stimulated & 147.6 & 146.5 & 150.5 & 116.1 & 7.32 \\
\hline
\end{tabular}

Data expressed as mean and pooled SEM. $n=16$ for BW and immune organ weights, $n=8$ for small intestine, Peyer's patch (PP) measurements and heterophil activities and $n=7$ for lymphocyte proliferation.

$\mathrm{a}, \mathrm{b}-$ Means within the same row with different superscripts differ significantly $(P<0.05)$.

${ }^{1}$ Dietary treatments - $\mathrm{A}=$ Arbocel $^{\mathbb{R}} \mathrm{RC}$ fine $1 \mathrm{~g} / 100 \mathrm{~g}$ basal diet; $\mathrm{Ce}=$ cellulose $1 \mathrm{~g} / 100 \mathrm{~g}$ basal diet; Ce3Lig1 $=3: 1$ mixture of cellulose: lignin, $1 \mathrm{~g} / 100 \mathrm{~g}$ basal diet; Ce2Lig $1=2: 1$ mixture of cellulose:lignin, $1 \mathrm{~g} / 100 \mathrm{~g} \mathrm{BW}$ basal diet.

${ }^{2}$ Standard ranges of body weights at 4 weeks $=257-273 \mathrm{~g}$, at 8 weeks $=650-690 \mathrm{~g}$, and at 9 weeks $=757-803 \mathrm{~g}$ (Hy-Line Brown International, 2015).

${ }^{3} \mathrm{PI}=$ phagocytosis index.

${ }^{4} \% \mathrm{P}=$ phagocytosis percentage.

${ }^{5} \triangle \mathrm{RFU}=$ change in relative fluorescence units after $1 \mathrm{~h}$ incubation with phorbol 12-myristate 13-acetate (PMA) (see methods for calculation).

${ }^{6}$ Lymphocyte proliferation expressed as a percentage of the increase in mitogen-stimulated lymphocytes relative to non-stimulated lymphocytes. Mitogens: ConA = concanavalin A, T lymphocyte mitogen; LPS=lipopolysaccharide from Escherichia coli, B lymphocyte mitogen; PMA = phorbol 12-myristate 13-acetate, mixed $\mathrm{T}$ and $\mathrm{B}$ lymphocyte mitogen.

observed previously (Hussein et al., 2017). The weight differences in the bursae are unlikely to be the result of involution due to the age difference of only one week in the two batches of pullets: the growth rate of the bursa starts to decrease at about 6-8 weeks of age and although strain differences can influence the age at which involution occurs, it has not been reported to affect weight before 12 weeks of age (Glick, 1956; Ciriaco et al., 2003; Rodríguez-Méndez et al., 2010; Oláh et al., 2014). Glick (1957) showed that cortisone administration reduced bursal size in young poultry; however, the pullets in this study were reared under conditions similar to that of the previous experiment, and it is therefore unlikely that stress elevated adrenal hormone levels. In addition, cortisone also reduces the weight of the thymus (Glick, 1957), and in this study, the weight of the thymus was only $14 \%$ lower than that observed previously (Hussein et al., 2017).

Although Glick and Dreesen (1967) have shown that the bursa can influence splenic and thymic growth, the relatively small differences in their weights between this study and our previous study (Hussein et al., 2017) suggest that the small size of the bursa had negligible effect on the relative sizes of the two other lymphoid tissues. In addition, the presence of small bursa in the pullets used here may not have affected the growth rate of the pullets, as the mean BW $(803.4 \pm 6.69 \mathrm{~g}$, mean \pm SE, $n=64$ ) at 9 weeks for all pullets was at the upper 
weight of the standard range (757-803 g) for the strain (HyLine Brown International, 2015). BW was also higher than that of the younger 8 -week-old pullets $(717.5 \pm 14.6 \mathrm{~g}, n=$ 12) of the same strain used in Hussein et al. (2017). In this study, the initial BW at 4 weeks was $349.5 \pm 6.4 \mathrm{~g}(n=16)$, whereas it was $351.9 \pm 4.7 \mathrm{~g}(n=12)$ in Hussein et al. (2017); both values are above the standard range for 4-week-old pullets (257-273 g, Hy-Line Brown International, 2015).

The number of PP in the jejunum and ileum of group A pullets was higher $(P<0.05, n=8)$ than those of group Ce (Table 2), and although the numbers were higher in groups Ce3Lig1 and Ce2Lig1 than in group Ce, the differences were not significant. Hussein et al., 2017 showed that Arbocel ${ }^{\mathbb{R}}$ RC fine significantly increased PP number, area, and relative area compared to the un-supplemented controls. The higher number of PP suggests that the presence of lignin and its concentration in a fiber supplement is important for the development of gut-associated lymphoid tissue. However, we could not identify the mechanism(s) via which the dietary supplements affected the PP; changes in microbial populations (Cao et al., 2003; Bogusławska-Tryk et al., 2015), mechanical effects of fiber on the mucosal surface of the gut (Baurhoo et al., 2008), increased amino acid availability (Yokhana et al., 2016; Farran et al., 2017), and cytokine production (Mendis et al., 2016) may all be contributing causes.

\section{Heterophil and Lymphocyte Functions}

Three weeks after starting the experimental diets, heterophil phagocytosis percentages $(\% \mathrm{P})$ in groups $\mathrm{A}$ and Ce3Lig1 were higher $(P<0.05, n=8)$ than in group Ce (Table 2$)$. Revajová et al. (2013) used a relatively higher concentration of lignin $(0.5 \mathrm{~g} / 100 \mathrm{~g}$ diet $)$ for a shorter time (2 weeks) and observed no effect on phagocytosis in 4-week-old broiler chickens compared to the un-supplemented controls. Heterophil oxidative burst activity was higher $(P<0.05, n=8)$ in group A pullets compared to that of pullets in group Ce (Table 2). Although phagocytosis values for groups Ce3Lig1 and Ce2Lig1 were higher than for group Ce, the differences were not significant.

The mechanism(s) via which heterophil function was improved could involve the antimicrobial characteristics of the phenolic fractions of purified lignin, which increased the proportions of beneficial cecal Lactobacillus and Bifidobacterium spp. and decreased that of E. coli, as has been demonstrated in broiler chicks (Baurhoo et al., 2008). In addition, Farnell et al. (2006) showed that heterophil oxidative burst and degranulation was improved in broilers administered an oral mixture of Lactobacillus and Bifidobacterium spp. on the day of hatching. However, the type of measurements used to determine the effects of the different IF are not sufficient for understanding the mechanistic effects of IF on organs and tissues.

The innate functions of heterophils are important defense mechanisms for young layer poultry, and the results obtained in this study suggest that phagocytosis and oxidative burst can be enhanced by administering diets supplemented with mixtures of purified lignin and cellulose similar to that ob- tained with the commercial lignocellulose product Arbocel ${ }^{\circledR}$ but not with cellulose alone. Wang et al. (2009) suggests that some of the different responses observed when plant sources of fiber such as oat hulls or alfalfa are used in animal diets are probably because of the different proportions of the functional groups of lignin (for example; hydroxyl, methoxy, carbonyl, and carboxyl groups) in various plants. Thus, it is possible that the differences observed in response to diets Ce3Lig1 and Ce2Lig1 were due to differences in the proportions of lignin functional groups.

No significant differences among the treatment groups were observed with respect to lymphocyte proliferation. However, proliferation tended to be higher in group A, followed by groups Ce2Lig1, Ce3Lig1, and Ce (Table 2). Revajová et al. (2013) have shown that lignin supplementation increases lymphocyte numbers in the villi of the intestinal tract (but not peripheral lymphocytes) and suggested that beneficial bacteria in the gut (Baurhoo et al., 2007) may contribute to the observed effect.

In this study, the proliferative response of lymphocytes to stimulation by the three mitogens was similar to that observed previously (Hussein et al., 2017), in which significant differences were observed among the three treatments $(n=$ 8). In this study, only seven replicate pullets/treatments were used and there were four treatments. Power analysis (Faul et al., 2009) of the data on ConA-stimulated lymphocytes shows that at least 13 replicates/treatment are required to observe significant differences between the treatments.

\section{Live Body Weight}

In addition to the effects on the immune system, differences were observed in live BW. After 5 weeks on experimental diets, BW in groups A and Ce3Lig1 were more $(P<$ 0.05 ) than in that in group Ce (Table 2). Ricke et al. (1982) used a higher lignin concentration in a semi-purified diet $(8$ $\mathrm{g} / 100 \mathrm{~g}$ of the purified Kraft lignin product Indulin) and showed that weight gain of New Hampshire $\times$ Columbian pullets fed Indulin from 8 to 22 days of age was higher than that of the controls who did not receive added fiber. However, their results showed no significant difference in weight gain in pullets administered the lignin supplement compared to those administered Solka-Floc ${ }^{\circledR}$, a product containing higher ratio of cellulose to lignin (approximately $90 \mathrm{~g} / 100 \mathrm{~g}$ cellulose and $3 \mathrm{~g} / 100 \mathrm{~g}$ lignin) than used in this study (Ricke et al., 1982). A different type of lignin called Alcell lignin (at either 1.25 or $2.5 \mathrm{~g} / 100 \mathrm{~g}$ of the diet), has been shown to significantly improve broiler weight gain compared to controls without the additive (Baurhoo et al., 2007). The proportions of lignin to cellulose in Arbocel $^{\circledR} \mathrm{RC}$ fine (based on the manufacturer's analysis) are similar to that used for diet Ce3Lig1, and the beneficial effects of these two diets on BW $(P<0.05)$ compared to that of diet Ce suggest that the presence of lignin in an IF supplement is important. In previous studies using similar aged Hy-Line Brown pullets, Yokhana et al. (2016) and Hussein et al. (2017) showed that Arbocel $^{\circledR}$ RC fine significantly improved BW compared to un-supplemented controls; this effect may have resulted from improved proteolytic digestive enzyme activity (Yokhana et 
al., 2016) and protein and amino acid digestibility (Farran et al., 2017).

Overall, the results of this study suggest that the presence of lignin in an IF supplement is more beneficial than the presence of cellulose alone. The proportions of lignin and cellulose might also be important for improving the immune function of pullets. Improvements were observed in lymphoid organ size, and heterophil immune function and growth in groups A and Ce3Lig1, compared to the other two groups (especially that supplemented with only cellulose). The supplement with 3:1 cellulose: lignin ratio exerted an effect similar to that of Arbocel $^{\mathbb{R}} \mathrm{RC}$ fine that has almost identical cellulose to lignin ratio. The experiment thus contributes to enhance information on the different effects of the two major components present in insoluble fiber on immunity however, it would have benefitted from an increase in the number of replicates, increasing the experimental time pullets were fed the diets and by comparisons between different batches of the same or different egg-laying strains: a more detailed analysis of the chemical composition of the supplements used would have provided a better means of identifying the biologically active components. Future experiments aimed at understanding the mechanisms underlying the action of different fibers will assist in predicting the effects of complex natural sources of fiber in poultry feed ingredients. Determining the contribution of factors such as hen health, incubation environment, and rearing practices in the first weeks of life to variations in lymphoid tissue development between batches of the same strain is also important as this may aid the poultry industry in improving the health and disease resistance of layers especially in their most vulnerable first weeks of life.

\section{Acknowledgments}

We thank the Ministry of Higher Education and Scientific Research (MHESR) of Iraq for the scholarship to S. M. Hussein, the MHESR-Kurdistan Regional Government and the University of Duhok, Kurdistan Region, Iraq, for granting him study leave, and the School of Life Sciences, La Trobe University, for support with a Postgraduate Publication Award while writing this paper. We thank Josefina Susbilla for assistance with locating the sources of lignin, and Rob Evans and the LARFT staff for assistance with care of pullets.

\section{References}

Akhtar M, Tariq AF, Awais MM, Iqbal Z, Muhammad F, Shahid M and Hiszczynska-Sawicka E. Studies on wheat bran arabinoxylan for its immunostimulatory and protective effects against avian coccidiosis. Carbohydrate Polymers, 90: 333-339. 2012.

Bach Knudsen KE. Carbohydrate and lignin contents of plant materials used in animal feeding. Animal Feed Science and Technology, 67: 319-338. 1997.

Baurhoo B, Phillip L and Ruiz-Feria C. Effects of purified lignin and mannan oligosaccharides on intestinal integrity and microbial populations in the ceca and litter of broiler chickens. Poultry
Science, 86: 1070-1078. 2007.

Baurhoo B, Ruiz-Feria C and Zhao X. Purified lignin: Nutritional and health impacts on farm animals - A review. Animal Feed Science and Technology, 144: 175-184. 2008.

Bogusławska-Tryk M, Szymeczko R, Piotrowska A, Burlikowska K and Śliżewska K. Ileal and cecal microbial population and short-chain fatty acid profile in broiler chickens fed diets supplemented with lignocellulose. Pakistan Veterinary Journal, 35: 212-216. 2015.

Cao B, Zhang X, Guo Y, Karasawa Y and Kumao T. Effects of dietary cellulose levels on growth, nitrogen utilization, retention time of diets in digestive tract and caecal microflora of chickens. Asian Australasian Journal of Animal Sciences, 16: 863-866. 2003.

Ciriaco E, Pinera PP, Diaz-Esnal B and Laura R. Age-related changes in the avian primary lymphoid organs (thymus and bursa of Fabricius). Microscopy Research and Technique, 62: 482-487. 2003.

Cornes JS. Number, size, and distribution of Peyer's patches in the human small intestine. Part I The development of Peyer's patches. Gut, 6: 225-229. 1965.

Corzo A, Kidd MT, Dozier WA, Pharr GT and Koutsos EA. Dietary threonine needs for growth and immunity of broilers raised under different litter conditions. Journal of Applied Poultry Research, 16: 574-582. 2007.

Faber TA, Dilger RN, Hopkins AC, Price NP and Fahey Jr. GC. Effects of oligosaccharides in a soybean meal-based diet on fermentative and immune responses in broiler chicks challenged with Eimeria acervulina. Poultry Science, 91: 31323140. 2012.

Farnell M, Donoghue AF, De Los Santos S, Blore P, Hargis B, Tellez G and Donoghue D. Upregulation of oxidative burst and degranulation in chicken heterophils stimulated with probiotic bacteria. Poultry Science, 85: 1900-1906. 2006.

Farran MT, Akilian, HA, Ali M. Hamoud AM, Barbour GW and Saoud IP. Lignocellulose improves protein and amino acid digestibility and egg hatchability in broiler breeders. Journal of Poultry Science, 54: 197-204. 2017.

Faul F, Erdfelder E, Buchner A and Lang A-G. Statistical power analyses using $G^{*}$ Power 3.1: Tests for correlation and regression analyses. Behavior Research Methods, 41: 1149-1160. 2009.

Gibbons JD and Chakraborti S. Nonparametric Statistical Inference., Springer, Berlin Germany. 2011.

Glick B. Normal growth of the bursa of Fabricius in chickens. Poultry Science, 35: 843-851. 1956.

Glick B. Experimental modification of the growth of the bursa of Fabricius. Poultry Science, 36: 18-23. 1957.

Glick B and Dreesen LJ. The influence of selecting for large and small bursa size on adrenal, spleen, and thymus weights. Poultry Science, 46: 396-402. 1967.

He H, Genovese K, Swaggerty CL, Nisbet DJ and Kogut MH. In vivo priming heterophil innate immune functions and increasing resistance to Salmonella enteritidis infection in neonatal chickens by immune stimulatory $\mathrm{CpG}$ oligodeoxynucleotides. Veterinary Immunology and Immunopathology, 117: 275-283. 2007.

Hussein SM, Yokhana JS and Frankel TL. Supplementing feeds of layer pullets at different ages with two different fiber sources improves immune function. Poultry Science, 96: 2718-2727. 2017.

Hy-Line Brown International. Hy-Line Brown Management Guide - 
Commercial layers 2015. http://www.hyline.com.au/wp-content/ uploads/2016/01/HL-Brown-Commercial-Manual-BRN-COMENG.pdf. Accessed on February 29, 2016.

Jiang JF, Song XM, Wu J and Jiang YQ. Effects of alfalfa meal on the intestinal microbial diversity and immunity of growing ducks. Journal of Animal Physiology and Animal Nutrition, 98: 1039-1046. 2014.

Kwak H, Austic R and Dietert R. Influence of dietary arginine concentration on lymphoid organ growth in chickens. Poultry Science, 78: 1536-1541. 1999.

McReynolds J, Genovese K, He H, Swaggerty C, Byrd J, Ricke S, Nisbet D and Kogut M. Alfalfa as a nutritive modulator in maintaining the innate immune response during the molting process. Journal of Applied Poultry Research, 18: 410-417. 2009.

Mendis M, Leclercb E and Simseka S. Arabinoxylans, gut microbiota and immunity. Carbohydrate Polymers, 139: 159-166. 2016.

Oláh I, Nágy N and Vervelde L. Structure of the Avian Lymphoid System. In: Avian Immunology (Schat KA, Kaspers B and Kaiser P eds.). Academic Press Boston, USA, 2014.

Palacios MG, Cunnick JE, Winkler DW and Vleck CM. Immunosenescence in some but not all immune components in a freeliving vertebrate, the tree swallow. Proceedings of the Royal Society B, 274: 951-957. 2007.

Revajová $\mathrm{V}$, Levkut $\mathrm{M}$, Levkutová $\mathrm{M}$, Bořutová $\mathrm{R}$, Grešaková $\mathrm{L}$, Košiková B and Leng L. Effect of lignin supplementation of a diet contaminated with Fusarium mycotoxins on blood and intestinal lymphocyte subpopulations in chickens. Acta Veterinaria Hungarica, 61: 354-365. 2013.

Ricke SC, Van der Aar PJ, Fahey GC and Berger LL. Influence of dietary fibers on performance and fermentation characteristics of gut contents from growing chicks. Poultry Science, 61: 1335-1343. 1982.

Rodríguez-Méndez AJ, Luna-Acosta JL, Carranza M, HarveyS, Arámburo $\mathrm{C}$ and Luna M. Growth hormone expression in stromal and non-stromal cells in the bursa of Fabricius during bursal development and involution: Causal relationships? General and Comparative Endocrinology, 167: 297-307. 2010.

Sadeghi A, Toghyani M and Gheisari A. Effect of various fiber types and choice feeding of fiber on performance, gut development, humoral immunity, and fiber preference in broiler chicks. Poultry Science, 94: 2734-2743. 2015.

Saki AA, Hemati Matin HR, Tabatabai MM, ZamaniP and Naseri Harsini R. Microflora population, intestinal condition and performance of broilers in response to various rates of pectin and cellulose in the diet. European Poultry Science, 74: 183-188. 2010.

Shakouri M, Kermanshahi H and Mohsenzadeh M. Effect of different non starch polysaccharides in semi purified diets on performance and intestinal microflora of young broiler chickens. International Journal of Poultry Science, 5: 557-561. 2006.

Wan CP, Myung E and Lau BHS. An automated micro-fluorometric assay for monitoring oxidative burst activity of phagocytes. Journal of Immunological Methods, 159: 131-138. 1993.

Wang Y, Marx T, Lora J, Phillip L and McAllister T. Effects of purified lignin on in vitro ruminal fermentation and growth performance, carcass traits and fecal shedding of Escherichia coli by feedlot lambs. Animal Feed Science and Technology, 151: 21-31. 2009.

Yokhana J, Parkinson G and Frankel TL. Effect of insoluble fiber supplementation applied at different ages on digestive organ weight and digestive enzymes of layer-strain poultry. Poultry Science, 95: 550-559. 2016.

Yu B, Tsai C-C, Hsu J-C and Chiou P-S. Effect of different sources of dietary fibre on growth performance, intestinal morphology and caecal carbohydrases of domestic geese. British Poultry Science, 39: 560-567. 1998.

Zhang B, Guo Y and Wang Z. Modulating effect of $\beta-1,3 / 1,6-$ glucan supplementation in the diet on performance and immunological responses of broiler chickens. Asian-Australasian Journal of Animal Science, 21: 237-244. 2008. 